\title{
COMPARING SOCIO-SPATIAL MOBILITY AND ITS OUTCOMES IN AUSTRALIA AND NEW ZEALAND
}

\author{
William A.V. Clark* \\ California Center for Population Research \\ University of California Los Angeles \\ (wclark@geog.ucla.edu)
}

\begin{abstract}
Households choose places from a hierarchy of options defined by social, economic and environmental contexts and these choices are conditioned by age, family status and economic contexts. While we know a good deal about the choice processes we know somewhat less about the spatial outcomes of these decisions apart from the well-established distance minimization of most moves. Recent research has begun to fill that gap and in this paper I unpack an earlier study of mobility across communities clustered by measures of disadvantage and extend that study to a comparable analysis of mobility in Australia. Specifically, I use the New Zealand Deprivation Index and the SEIFA index in the Household Income and Labour Dynamics Survey in Australia (HILDA) to construct matrices of socio-spatial movement and consider the relationship between in-flows and out-flows, the interaction of moves with age and education and the relationship of initial location with mobility outcomes.
\end{abstract}

\section{Introduction}

In a previous presentation at the 14th Labor Employment and Work conference with Philip Morrison we examined the nature of residential sorting and the movement across the hierarchy of neighbourhoods in New Zealand defined by the New Zealand deprivation index. That study (Clark and Morrison, 2012) provided some of the first evidence of the nature of movement within the social structures of New Zealand. A companion paper (Morrison and Nissen, 2010) used New Zealand census data to provide similar analyses of residential movement across neighbourhoods on an aggregate basis. In the Clark and Morrison (2012) paper we were able to show that the probability of leaving the very deprived areas was modestly lower than expected especially if the household was a low income or minority household. In contrast, more educated and above average income households were more likely to make gains. The present paper is designed to extend that study of residential sorting and choice and the associated residential mobility.

There is growing interest in the nature of social mobility especially a growing concern with intergenerational social mobility which addresses the issue of how to interrupt the transmission of disadvantage from one generation to another. The concern with intergenerational mobility in the United Kingdom has been formalized in a strategy for social mobility published by the current government. In the UK context this is not just about intergenerational social mobility it is also about ensuring that whatever an individual's background the that they have an equal chance of reaching a higher income bracket, getting a job they want, and from the perspective of this study achieving the spatial mobility that often goes with social mobility. Drawing on the notions of social mobility the British government's argument is that a fluid society (the ability to move up the social ladder) is probably a better society with greater opportunities and fewer barriers to success.

Following these ideas this paper explores the extent and nature of socio-spatial fluidity across the national contexts of New Zealand and Australia. Specifically the paper unpacks the sorting in the flow matrices of population moves across neighbourhoods scaled by the New Zealand deprivation index and the Australian Socio Economic Index of disadvantage (SEIFA). Specifically, the paper asks what proportion of movers are (a) potentially locked in at the bottom of the disadvantage scale (b) how much "sideways" movement is there in the flow matrix (moves which begin and end in similar communities) and (c) for those households in the least disadvantaged areas what is the likelihood of losing status associated with mobility. The paper thus unpacks the flow matrices by age and education to examine the role of these variables in creating differential flow patterns across neighbourhoods and communities within New Zealand. 


\section{Theoretical Context}

Although it has been difficult to document the effects of specific neighbourhoods and communities on family and child outcomes there is still a strongly held consensus that the neighbourhoods in which we live are an important factor in our opportunity structures. Those who live in better neighbourhoods do have access to better schools, and likely to a whole range of externalities that are associated with higher status neighbourhoods and communities. At the simplest level we tend to believe that moving to a more advantaged neighbourhood is associated with greater opportunities, and, at the same time, an escape from the problems that are often concentrated in less advantaged places. But even for those already in neighbourhoods which are some way above the least advantaged, movement to higher status neighbourhoods may bring further social gains. Clearly, the Strategy for Social Mobility report published in the United Kingdom believes that greater social fluidity benefits society as a whole and that a more open and fluid society could bring gains in both productivity and subjective well-being through the reduction of social isolation (Cabinet Office, 2011).

Of course it may be that the neighbourhoods we live in simply reflect our socio-economic position in society. In one view it is simply our purchasing power that determines the types of places that we can access and, of course, the externalities along with that purchase (Cheshire, et al. 2003). This is not to argue that places do not matter but rather that it is a complicated interaction between household status and the places in which households are located. As Cheshire (2012) notes, the issue is about causation. What evidence do we have that poor neighbourhoods make residence poorer or is it simply that poor people live in poor neighbourhoods because it costs too much to live in more affluent ones?

This question has not been resolved - that is whether living in a poor neighbourhood is a separate and additional cause of poverty or a reduction in the number of opportunities for families living in those neighbourhoods than the effect created by the family structure itself. What we know from the research to date is that many of the goods that we consume in the urban environment can only be consumed by living in the appropriate place. The obvious example is the consumption of good schools. And, studies have shown that access to public transportation and a variety of other urban amenities is reflected in house prices. Indeed as Cheshire (2012) argues more generally, hedonic studies of housing markets confirm that access to amenities, greater security, and good access to public services are all capitalized into house prices. Thus, house prices in fact reflect underlying differences in access to opportunities.

This contextual discussion is relevant for the larger policy issue of how we respond to initiatives to overcome poverty and disadvantage more generally. Do we focus on places - a place based approach - or on people? The "place prosperity vs. people prosperity has been a continuing and lively debate (Bolton, 1992), nor is there any resolution in how to address the continuing concentration of poverty populations. What is relevant is that we continue to probe the structure of the clustering of disadvantage populations and at the other end of the continuum the behaviour and clustering of advantaged populations. For Cheshire the lack of any strong evidence for neighbourhood affects suggest that we proceed with caution in any policy that is simply place based. By implication as has been argued elsewhere (Clark, 2012) it might be more useful to focus on education as a solution to inequality rather than on welfare subsidies either to people or places.

\section{Previous research}

There is a literature which has considered movement across a matrix of neighbourhoods though the tendency has been to focus more on movement across different ethnic contexts than different socio economic contexts. There have been modest attempts to examine the movements between a full range of neighbourhoods defined in socio economic terms (Bolt et al., 2008; Clark and Rivers, 2012). Recently, a New Zealand study of movement across a set of neighbourhoods found that the degree of upward mobility achieved is negatively affected by the level of deprivation at the neighbourhood of origin. Even after controlling for the attributes of movers, the more deprived the neighbourhood of origin, the lower the degree of upward mobility movers experience (Clark and Morrison, 2012). However, the effect is small. In the British context Clark et al (2012) have shown the structure of the housing market is an important factor in the nature of movement through the structure of communities.

Two recent British studies have taken up the issue of residential mobility, tenure and the inter-relationship with neighbourhood contexts (Boheim and Taylor, 2002; Rabe and Taylor, 2010). These studies specifically address actual moves between neighbourhoods and regions. While the first of these studies is more concerned with the joint housing and job mobility process, the authors establish that a desire to move motivated by employment reasons is most likely to generate moves between regions, and it is unemployed renters who are most likely to move. Even more directly, Rabe and Taylor (2010) focus on neighbourhoods themselves to show that life course events do not always lead to neighbourhood quality adjustments. The question in the Rabe and Taylor (2010) study is about objective and subjective gains when moving between neighbourhoods.

European work has shown how net migration flows reflect residential sorting behavior and thereby reinforce deprivation in such areas regardless of the macro- economic context. Gramlich et al (1992) and Anderson and Brama (2004) each show that even though the poor as a whole are quite mobile, there is a tendency of people who move into deprived areas to be poorer than those on average in the area which leads to increased neighbourhood deprivation (Anderson and Brama, 2004). In the European context Bolt and van Kempen show that native Dutch households (in 
contrast to ethnic minorities) are more likely to be able to leave poor neighbourhoods. The fact that out-migration of the non-poor renders poor areas even more disadvantaged tends to reinforce the relative ranking of neighbourhoods, perpetuating the socio-economic separation of neighbourhoods particularly when the differences between them are marked to begin with.

In the US context those studies which have taken up the issue of community and neighbourhood mobility have tended to focus primarily on movement into and out of low income communities. Quillian (2003) shows that non-poor blacks are more likely than poor blacks to choose predominantly white residential neighbourhoods when they move. Blacks who move out of predominantly white tracts are significantly more likely to move to another predominantly white tract and make up a small percentage of all non-whites in that particular tract. This mobility behaviour is consistent with mobility behaviour in general wherein minorities attempt to leave marginal lower class and lower middle class neighbourhoods for middle class neighbourhoods. This process means that single parent minority households who tend to be poorer will end up in poorer neighbourhoods with lower probabilities of being able to leave those neighbourhoods. It is here that the intersection of changes in life circumstances and residential location can interact - thus unemployment and being unmarried can limit the accumulation of human capital and the income necessary for moving to, and living in predominantly owner occupied housing. At the same time, South and Crowder (1997) show that blacks are less likely than whites to leave poor tracts and are more likely to move into them.

The process of moving on or being "trapped", in poor neighbourhoods is clearly related to resources. Education, employment and training have the potential to stimulate mobility out of deprived areas. To the extent that they are successful, 'those who get on, get out' and this lowers rather than raises the average level of deprivation in the area being assisted (Cheshire, et al. 2003). Several studies have demonstrated empirically the influence of income and socio-economic status on movements in and out of deprived neighbourhoods (South, Crowder and Chavez. 2005; South Pais and Crowder, 2011, Bolt, van Kempen et al. (2008). And, as Schaake et al (2009) point out, people with higher income are more likely to move out of neighbourhoods through a sorting process which reinforces the concentrations of the have and have-nots into selected neighbourhoods. Recent research has shown that spatial sorting continues to operate even in communities where there is a strong policy interest in mixing, for example in the Dutch context (Van Ham and Feijten, 2008). This is partly because mobility decisions can be triggered by the presence of minority populations (Bolt and van Kempen 2008).

\section{Data - The Survey of Dynamics and Motivation for Migration and HILDA}

The data for this analysis of mobility across deciles of disadvantage come from two sources. The source for the New Zealand data is a statistics New Zealand survey, the Dynamics and Motivation for Migration which was designed to investigate the motivations behind residential mobility. In the March 2007 quarter of the Labor Force survey a sample of 26,756 respondents were given an opportunity to take part in the migration supplement leading to a total of 23,465 completed additional questions. I use the data for those who moved within New Zealand in the two years prior to the interview. It is the same data set which was the basis for the Clark and Morrison (2012) paper on residential sorting. As in the previous paper I examine the changes in their neighbourhood location as measured by the rating the neighbourhood receives on the basis of the New Zealand Deprivation Index. Based on the ideas of the UK Townsend index (Townsend 1979), the New Zealand index is constructed from a set of nine variables representing a variety of elements of deprivation. The index is used to classify New Zealand communities and neighbourhoods into deciles of disadvantage, which are mapped in the Atlas of Socioeconomic Deprivation in New Zealand (White, et al. 2008). The neighbourhoods have on average 2200 people and they correspond closely to recognized names and identities of suburbs, especially in the larger urban areas where statistical boundaries have been relatively stable over many decades

The data for Australia come from the first 10 waves of the Household Income and Labor Dynamics in Australia survey (HILDA). The survey is a longitudinal survey of approximately 7,600 households with about 19,900 respondents. The survey is modeled on and is similar to surveys in the US (the Panel Study of Income Dynamics, PSID) and the British Households Panel Survey, now the "Understanding Society" study. In the present study the mobility measures and variables are drawn from the primary respondent representing the household. A consequent analysis will explore the effects of multiple person responses in the household for multi-person households. It is a yearly survey begun in 2001 and is ongoing. The survey in Australia covers a wide array of economic and labor market measures but also has detailed data on household composition and migration. Unlike most other panel surveys the HILDA survey collects data on perceived outcomes of residential location and satisfaction with a set of measures of housing, neighbourhood and community satisfaction. These values will be an integral part of future analyses. 


\section{Analysis - the New Zealand Experience}

\section{Matrices of flows and fluidity across communities}

As the previous presentation at the last LEW conference noted, the matrix of community exchange is well populated. ${ }^{1}$ There are substantial numbers of observations in all most all the cells (Table 1). The diagonal cell values (percentages here) represent the degree of stability exhibited by movers in their choice of neighbourhood (in NZDep06 terms). They represent the probability that someone who changes their address in the survey interval will remain within the same socio-economic band implied by the disadvantage index value (Table 2). As was emphasized in the previous presentation, the stability is quite independent of their choice of geographic location because a disadvantage level can appear anywhere within the country. The focus therefore is purely on mobility across the deciles of deprivation and not across geography per se.

\section{Table 1: Flows across the matrix of community disadvantage}

\begin{tabular}{|c|c|c|c|c|c|c|c|c|c|c|c|}
\hline & Most & & Disad & tage & us De & natio & lecile & vave & & Least & \\
\hline & 1 & 2 & 3 & 4 & 5 & 6 & 7 & 8 & 9 & 10 & Total \\
\hline 1 & 203 & 124 & 68 & 49 & 44 & 23 & 30 & 13 & 8 & 6 & 568 \\
\hline 2 & 79 & 152 & 104 & 65 & 54 & 34 & 19 & 40 & 33 & 16 & 596 \\
\hline 3 & 82 & 135 & 159 & 50 & 76 & 58 & 38 & 40 & 14 & 21 & 673 \\
\hline 4 & 52 & 67 & 95 & 57 & 67 & 57 & 37 & 38 & 26 & 28 & 524 \\
\hline 5 & 36 & 77 & 91 & 48 & 84 & 43 & 35 & 42 & 32 & 31 & 519 \\
\hline 6 & 36 & 52 & 65 & 51 & 58 & 38 & 44 & 60 & 29 & 21 & 454 \\
\hline 7 & 37 & 66 & 42 & 47 & 77 & 49 & 65 & 57 & 33 & 28 & 501 \\
\hline 8 & 24 & 29 & 40 & 38 & 49 & 42 & 57 & 72 & 43 & 29 & 423 \\
\hline 9 & 16 & 34 & 36 & 31 & 34 & 38 & 29 & 31 & 40 & 43 & 332 \\
\hline 10 & 22 & 27 & 33 & 25 & 28 & 34 & 37 & 38 & 49 & 51 & 344 \\
\hline Total & 587 & 763 & 733 & 461 & 571 & 416 & 391 & 431 & 307 & 274 & 4934 \\
\hline
\end{tabular}

As this data was presented previously I reiterate three points. One, the most likely outcome when someone changes address is that they remain within the same decile (regardless of where they move geographically). Two, when one does move to another neighbourhood the chances of doing so decline the further away the destination is in disadvantage terms. Three, the probability of staying with the most disadvantaged communities is more than two times the probability of maintaining residence in the least disadvantaged communities.

\footnotetext{
${ }^{1}$ Note that the matrix in this discussion in contrast to the previous LEW presentation has been repositioned so that the most disadvantaged deciles are labeled 1, 2 and the least disadvantaged are 9,10.
} 
Table 2: Row percentages of mobility (conditional probabilities)

\begin{tabular}{|c|c|c|c|c|c|c|c|c|c|c|c|}
\hline & \multicolumn{2}{|l|}{ Most } & \multicolumn{6}{|c|}{ Disadvantage Status Destination decile wave } & \multicolumn{3}{|c|}{ Least } \\
\hline & 1 & 2 & 3 & 4 & 5 & 6 & 7 & 8 & 9 & 10 & Total \\
\hline 1 & 35.74 & 21.83 & 11.97 & 8.63 & 7.75 & 4.05 & 5.28 & 2.29 & 1.41 & 1.06 & 568 \\
\hline 2 & 13.26 & 25.50 & 17.45 & 10.91 & 9.06 & 5.70 & 3.19 & 6.71 & 5.54 & 2.68 & 596 \\
\hline 3 & 12.18 & 20.06 & 23.63 & 7.43 & 11.29 & 8.62 & 5.65 & 5.94 & 2.08 & 3.12 & 673 \\
\hline 4 & 9.92 & 12.79 & 18.13 & 10.88 & 12.79 & 10.88 & 7.06 & 7.25 & 4.96 & 5.34 & 524 \\
\hline 5 & 6.94 & 14.84 & 17.53 & 9.25 & 16.18 & 8.29 & 6.74 & 8.09 & 6.17 & 5.97 & 519 \\
\hline 6 & 7.93 & 11.45 & 14.32 & 11.23 & 12.78 & 8.37 & 9.69 & 13.22 & 6.39 & 4.63 & 454 \\
\hline 7 & 7.39 & 13.17 & 8.38 & 9.38 & 15.37 & 9.78 & 12.97 & 11.38 & 6.59 & 5.59 & 501 \\
\hline 8 & 5.67 & 6.86 & 9.46 & 8.98 & 11.58 & 9.93 & 13.48 & 17.02 & 10.17 & 6.86 & 423 \\
\hline 9 & 4.82 & 10.24 & 10.84 & 9.34 & 10.24 & 11.45 & 8.73 & 9.34 & 12.05 & 12.95 & 332 \\
\hline 10 & 6.40 & 7.85 & 9.59 & 7.27 & 8.14 & 9.88 & 10.76 & 11.05 & 14.24 & 14.83 & 344 \\
\hline Total & 587 & 763 & 733 & 461 & 571 & 416 & 391 & 431 & 307 & 274 & 4934 \\
\hline
\end{tabular}

The table can also be used to address the debate over residential polarization - how the relative shifts into and out of deciles creates concentrations of poverty and wealth. Any change can be measured as a difference in the probability of moving from $\mathrm{i}$ to $\mathrm{j}$ compared to moving in the other direction, from $\mathrm{j}$ to $\mathrm{i}$. The probability that someone will move from disadvantage 1 to disadvantage 2 is $\mathrm{p}_{12}$ and in the reverse direction is $\mathrm{p}_{21}$. As Morrison and Nissan (2010) point out, if movement was symmetrical throughout the matrix, that is if $\mathrm{p}_{12}=\mathrm{p}_{21}$, then there would be no net shift in the DMM population either into out of deprived areas. This can be visualized in Table 2 and is summarized in Figure 1 where the 45 corresponding (off-diagonal) pairs of transitions in Table 2 are plotted. If the corresponding transitions were equal, all points would lie along the 45 degree line. Off-diagonal points therefore indicate net gains and losses to other deciles. The overall level of correspondence between the probability of arriving and leaving any given disadvantage decile is relatively modest $\left(r^{2}=0.32\right)$. The slope is less than unity implying that there is a higher probability of moving to more disadvantaged areas. As we have discussed elsewhere there is strong evidence for regression to the mean - moves up from lower advantage areas and down from higher advantage areas and that is explored further in a later section. It is useful to note that there is a wide scatter for the DMM survey and it is significantly greater than for the aggregated moves for the Census data as a whole where the fit is $r^{2}=.75$ (Morrison and Nissan, 2010).

Figure 1: Flows across New Zealand areas of disadvantage

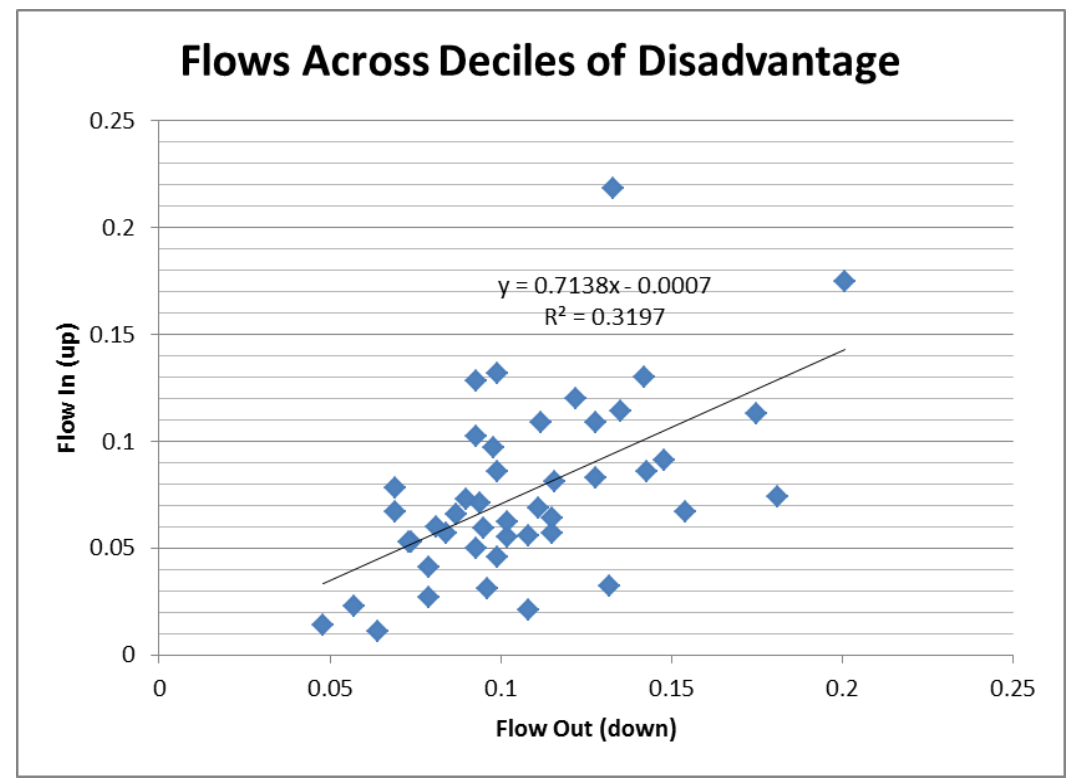


The major finding revealed in this plot of sample moves is the extensive circulation among all categories of neighbourhoods. In both periods there is a non-zero probability that someone will move from origin $\mathrm{i}$ to destination $\mathrm{j}$ regardless of how far they are apart in terms of disadvantage. Still, the further away in disadvantage terms a destination is from that of the origin, the less likely someone is to move there regardless of whether one is moving up or down in deprivation terms.

\section{Stability fluidity and outcomes across age and} education in New Zealand

A summary of the flow patterns emphasizes both the stability and fluidity in the system (Table 3). Nearly 43 percent of all moves are on the diagonal or one decile up or down from the diagonal. At the same time a quarter move up and about a third move down. These patterns are not especially influenced by age or education measured in broad categories although lower education status does have an effect (Table 3).

Table 3: Stability and fluidity in the New Zealand matrix of moves

\begin{tabular}{|l|l|l|l|l|l|}
\hline & All moves & $<35$ years & 35 years + & High School & Post HS \\
\hline Diagonal+/- & 2097 & 1065 & 772 & 1292 & 795 \\
\hline Percent & $\mathbf{4 2 . 5}$ & $\mathbf{4 2 . 6}$ & $\mathbf{4 2 . 0}$ & $\mathbf{4 5 . 0}$ & $\mathbf{3 8 . 5}$ \\
\hline Moves up & 1277 & 605 & 530 & 697 & 576 \\
\hline Percent & $\mathbf{2 5 . 9}$ & $\mathbf{2 4 . 2}$ & $\mathbf{2 8 . 9}$ & $\mathbf{2 4 . 3}$ & $\mathbf{2 7 . 9}$ \\
\hline Moves down & 1560 & 831 & 535 & 881 & 693 \\
\hline Percent & $\mathbf{3 1 . 6}$ & $\mathbf{3 3 . 2}$ & $\mathbf{2 9 . 1}$ & $\mathbf{3 0 . 6}$ & $\mathbf{3 3 . 6}$ \\
\hline$n$ & 4934 & 2501 & 1837 & 2870 & 2064 \\
\hline
\end{tabular}

\section{Outcomes by age and education}

If we focus on the extremes of the matrix that is the probability of moving and staying in the most and least disadvantaged quintiles, and on the probability of moving from the lowest to the highest and conversely from the highest to lowest areas of advantage, we can see some implications of age and education (Figure 2). There are different outcomes, a visual demonstration of the coefficients in the models of mobility in the Clark and Morrison (2012) paper. Age and education create differential mobility outcomes and concentrations of advantage and disadvantage. For age the differences occur in the most advantaged quintile. In the age diagram younger movers can sustain their location in high status areas or choose lower status areas as they make tenure transitions - a working hypothesis which cannot be tested with the DMM data. Older movers are twice as likely to be able to maintain their status, though even in this case it is only slightly more than a third of movers already in the highest status quintile.

For education the differences are played out more strongly for those who begin in areas of greater disadvantage - here low education increases the likelihood of moving and staying with the least advantaged areas and lowers the probability of moving to the very most advantaged quintile, in comparison with those who have post-high school education. While age (and by implication income) has distinct outcomes for movement in the most advantaged areas the difference for education are modest - possibly a response to the coding of the education variable. 
Figure 2: Outcomes at the margins for age and education in New Zealand

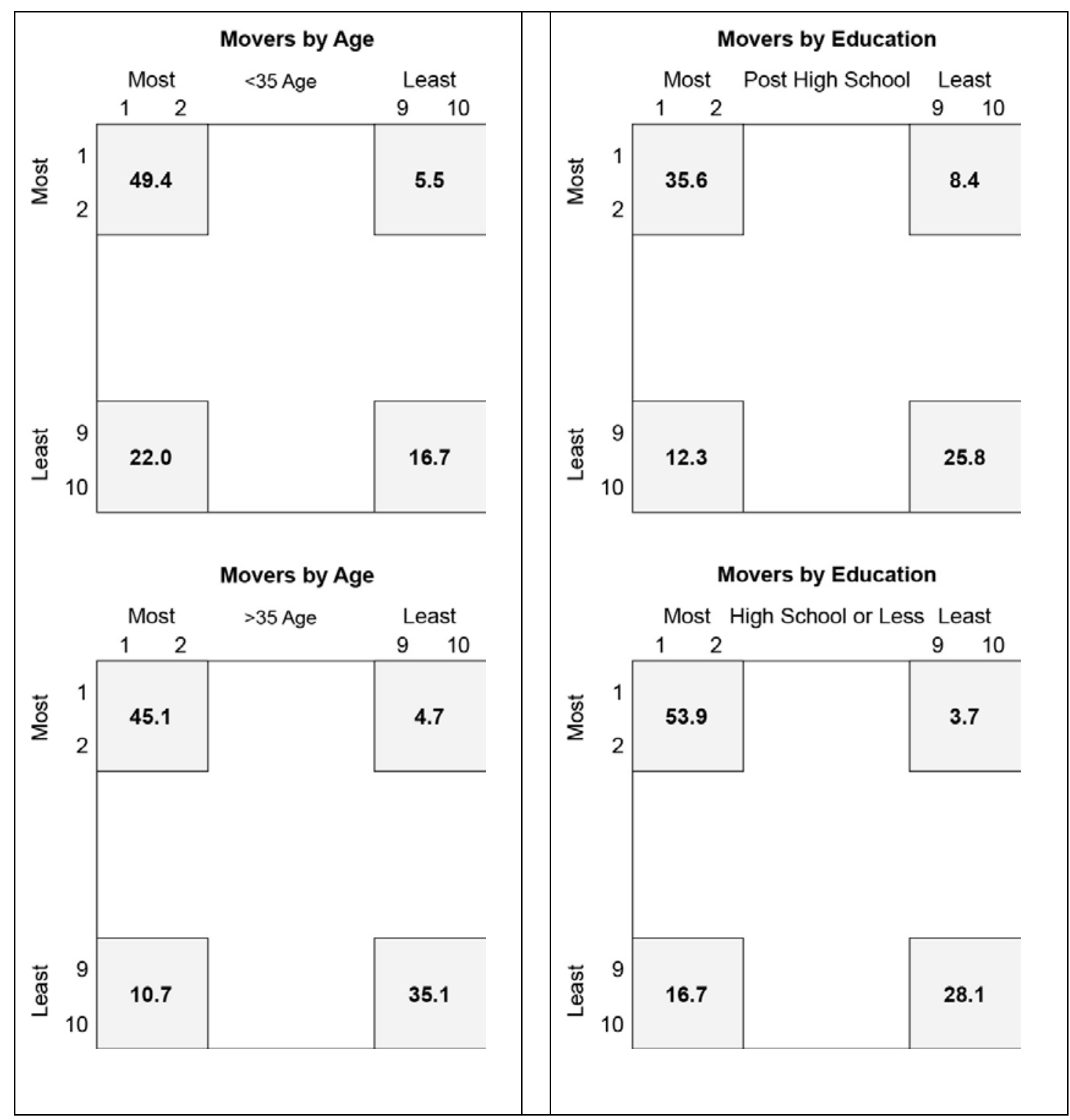




\section{Analysis - the Australian Experience}

\section{Matrices of flows and fluidity}

As for the New Zealand matrix the cells are well populated across the Australian matrix of disadvantage. The data in table 4 are the percentages -it is unnecessary to also include the actual move numbers. The diagonal cell values (percentages here) represent the degree of stability exhibited by movers in their choice of neighbourhood. They represent the probability that someone who changes their address between one year and the next in the panel data will remain within the same socio-economic band implied by the disadvantage index value. As was emphasized in the previous presentation, the stability is quite independent of their choice of geographic location because a disadvantage level can appear anywhere within the country. The focus therefore is purely on mobility across the deciles of deprivation and not across geography per se.

Table 4: Moves across the deciles of disadvantage in Australia

\begin{tabular}{|c|c|c|c|c|c|c|c|c|c|c|c|}
\hline & \multicolumn{2}{|l|}{ Most } & \multicolumn{6}{|c|}{ Disadvantage Status Destination decile wave } & \multicolumn{3}{|c|}{ Least } \\
\hline & 1 & 2 & 3 & 4 & 5 & 6 & 7 & 8 & 9 & 10 & Total \\
\hline 1 & 29.05 & 16.22 & 14.84 & 11.81 & 7.97 & 7.56 & 4.7 & 4.01 & 2.41 & 1.43 & 1745 \\
\hline 2 & 14.57 & 18.89 & 16.39 & 13.58 & 11.65 & 8.69 & 5.98 & 5.72 & 3.02 & 1.51 & 1922 \\
\hline 3 & 10.28 & 17.64 & 18.03 & 14.11 & 10.78 & 9.49 & 8.2 & 5.76 & 3.97 & 1.74 & 2013 \\
\hline 4 & 9.6 & 12.12 & 15.14 & 13.05 & 13.17 & 11.88 & 10.65 & 6.09 & 5.17 & 3.14 & 1625 \\
\hline 5 & 6.32 & 9.91 & 11.98 & 11.19 & 13.31 & 12.58 & 11.61 & 11.91 & 8.39 & 2.8 & 1645 \\
\hline 6 & 5.43 & 8.91 & 10.12 & 10.66 & 13.81 & 11.39 & 15.82 & 11.93 & 6.84 & 5.09 & 1492 \\
\hline 7 & 5.66 & 7.25 & 9.98 & 7.44 & 12.46 & 12.59 & 14.56 & 13.6 & 10.49 & 5.98 & 1573 \\
\hline 8 & 5.06 & 5.32 & 7.85 & 7.34 & 9.49 & 10.25 & 12.22 & 15.32 & 16.52 & 10.63 & 1580 \\
\hline 9 & 3.01 & 3.98 & 6.14 & 4.43 & 8.13 & 10.28 & 13.3 & 12.78 & 17.73 & 20.23 & 1760 \\
\hline 10 & 1.88 & 2.46 & 2.88 & 5.02 & 4.08 & 7.11 & 8.83 & 11.45 & 20.75 & 35.55 & 1913 \\
\hline Total & 1593 & 1809 & 1975 & 1713 & 1786 & 1737 & 1787 & 1669 & 1639 & 1560 & 17268 \\
\hline
\end{tabular}

A visual comparison across corresponding cells within Table 4 suggests a lower scatter than in the New Zealand case and the plot of off diagonal cells confirms this finding (Figure 3). The points lie closer to the 45 degree line and the overall level of correspondence between the probability of arriving and leaving any given disadvantage decile is relatively strong $\left(\mathrm{r}^{2}=0.84\right)$. The slope is greater than one, implying that there is a higher probability of moving to less disadvantaged areas.

Figure 3: Flows across Australian deciles of disadvantage

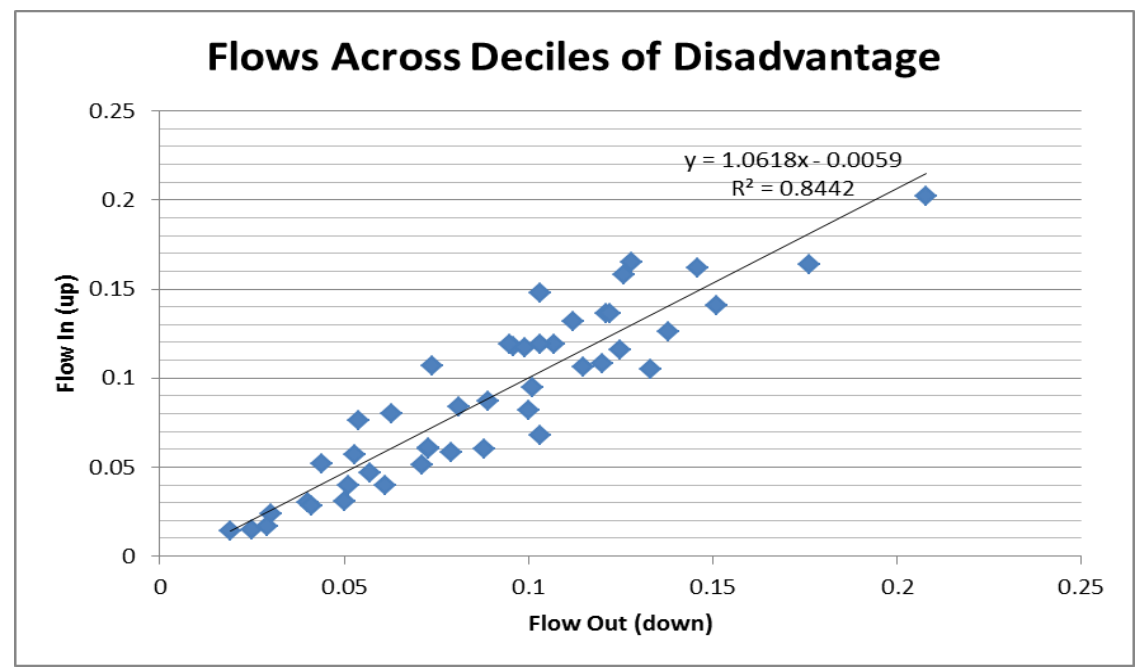


Stability fluidity and outcomes across age and education in Australia

Again, a summary of the flow patterns emphasizes both the stability and fluidity in the system (Table 5). Forty-six percent of all moves are on the diagonal or one decile up or down from the diagonal and a slightly higher percent move up as against moving down in advantage status. These patterns are somewhat more influenced by age and education than were the New Zealand distributions but the result for education is not strictly comparable (Table 5). Still, and as expected, the diagonal and adjacent deciles play a stronger role in the Australia matrix.

\section{Outcomes across age and education}

For Australia the extremes of the matrix for education provide greater contrasts than for the New Zealand data (Figure 4). This is not true for age. In the Australian context age plays a quite modest role. Older households have a slightly greater chance of maintaining residence in high status areas but overall the in the four extreme quintiles on age are quite small.
In contrast education creates strong differential mobility outcomes and concentrations of advantage and disadvantage for the extreme quintiles. Migrants who begin in the most advantaged areas and who have a BA are very much more likely to be able to maintain their status, and to move up to the most advantaged quintile. Those in the lowest quintile who have degrees are two and a half times more likely to move up than are those with lower educational achievement.

There is clearly greater resilience in the quintile matrix than is true for the New Zealand data. For now we can only speculate on the nature of this resilience and whether it is an outcome of the time frames of the two data sets. Philip Morrison has suggested that the period of the DMM survey was characterized by relatively steady growth, a strong demand for labor resulting in not only a lower unemployment rate but one in which gaps in unemployment by education dropped noticeably. In this sense with a slowing of inequality we might expect more opportunity and consequently more variability in the New Zealand outcomes.

Table 5: Stability and fluidity in the Australia matrix of moves

\begin{tabular}{|l|l|l|l|l|l|}
\hline & All moves & $<35$ years & 35 years+ & High School & BA+ \\
\hline Diagonal+/- & 7951 & 4252 & 3787 & 4129 & 1758 \\
\hline Percent & $\mathbf{4 6 . 0}$ & $\mathbf{4 4 . 4}$ & $\mathbf{4 9 . 2}$ & $\mathbf{4 7 . 1}$ & $\mathbf{4 7 . 6}$ \\
\hline Moves up & 4677 & 2691 & 1969 & 2332 & 953 \\
\hline Percent & $\mathbf{2 7 . 1}$ & $\mathbf{2 8 . 1}$ & $\mathbf{2 5 . 6}$ & $\mathbf{2 6 . 6}$ & $\mathbf{2 5 . 8}$ \\
\hline Moves down & 4640 & 2631 & 1938 & 2309 & 981 \\
\hline Percent & $\mathbf{2 6 . 9}$ & $\mathbf{2 7 . 5}$ & $\mathbf{2 5 . 2}$ & $\mathbf{2 6 . 3}$ & $\mathbf{2 6 . 6}$ \\
\hline$n$ & 17268 & 9574 & 7694 & 8770 & 3692 \\
\hline
\end{tabular}


Figure 4: Outcomes at the margins for age and education in Australia

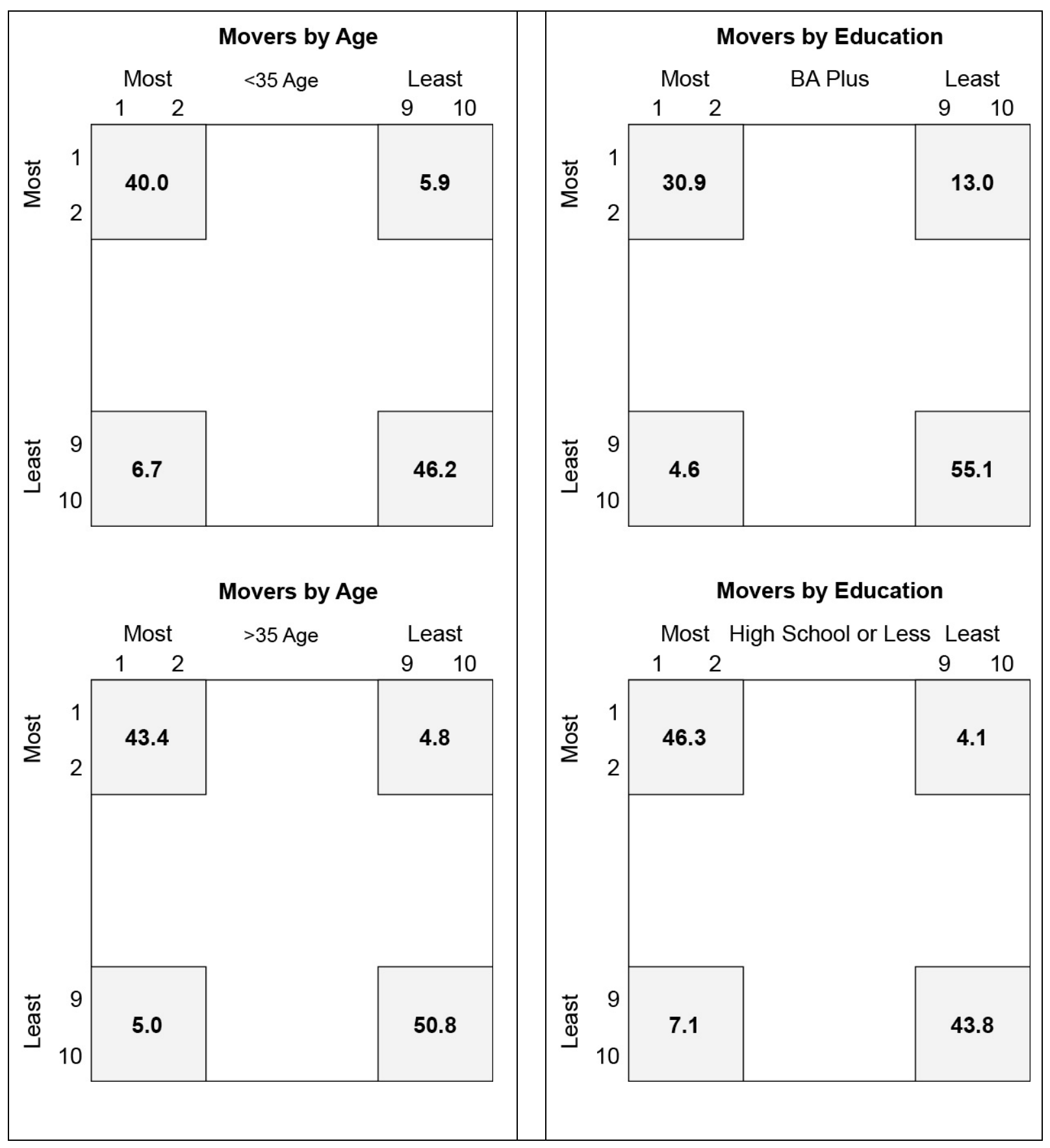




\section{Observations on National Outcomes}

Any comparisons across national contexts must be undertaken with considerable care because the data for New Zealand is from a one- time survey with moves over a two-year interval while the data from Australia is a ten year panel data set. These differences alone make comparisons difficult. Even so it is useful to put the average results side-by-side. I also introduce results from the British Household Panel Study as a context within which I can comment on the data for Australia and New Zealand (Figure 5)

Figure 5: Moves within the most and least advantaged areas in the UK, New Zealand and Australia
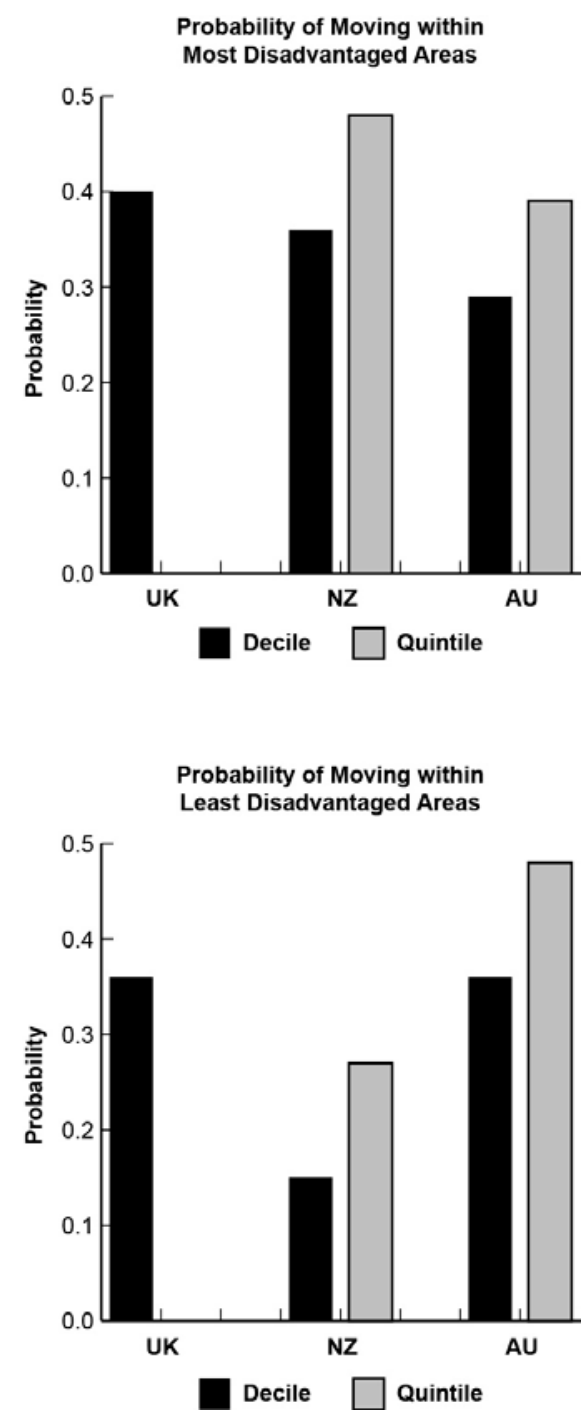

The probability of moving within the most disadvantaged areas of the United Kingdom New Zealand and Australia ranges around .35 to .45. The probability of moving within the lowest quintile is somewhat higher for New Zealand compared to Australia but again we must be careful because of the different sample frame. When we turn to the likelihood of moving within the least disadvantaged communities we find somewhat greater differences between Australia and New Zealand. This Australian outcome seems much more like the British context although again in that instance they are both panel data sets whereas New Zealand is a two-year sample frame. If nothing else these results stress the difficulty of comparisons across national contexts with different data sets.

One of the more interesting questions in these kinds of analyses is the extent to which the origin decile has an influence on the probability of moving to the most advantaged areas. Two graphs are structured to show the probability of moving to the three highest deciles by the origin decile (Figure 6). The graphs show that the probability increases as the status of the decile increases. Thus, someone in beginning in decile six has a five times greater likelihood of achieving movement to the upper deciles in comparison with a person beginning in the lowest decile. In a sense this is another way of documenting the opportunity matrix of flows which has underpinned the presentation to this point.

While there is considerably more research to be done on this part of the analysis it is clear that age has some effect in New Zealand and having a bachelor's degree is significant for moves in Australia. That education does not play a greater role in New Zealand is almost certainly due to the classification scheme used in the analysis. 
Figure 6: The probability of moving to deciles 7-9 by decile of origin. Note that the probabilities for moves from decile 7 include moves within that decile

(a) New Zealand

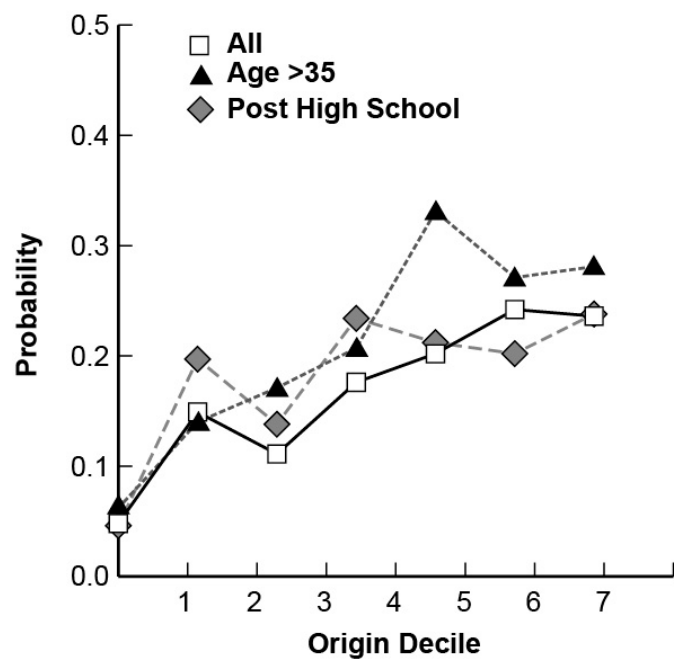

(b) Australia

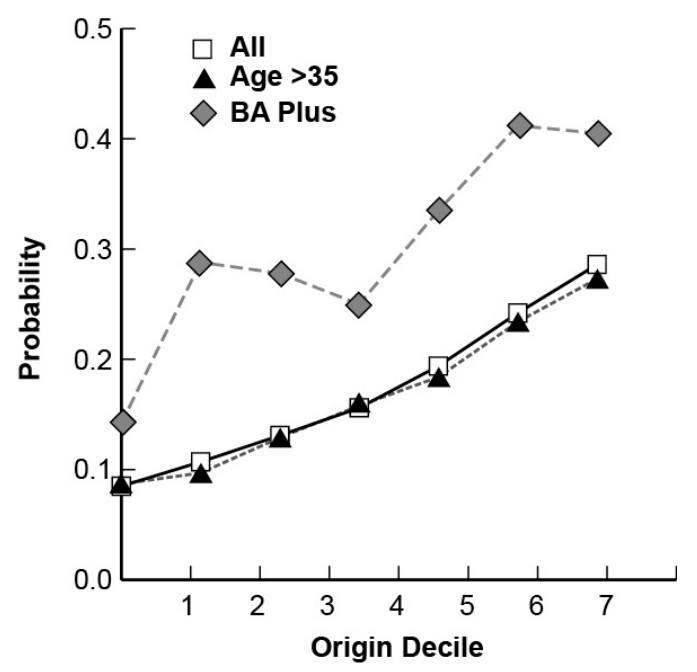

\section{Conclusions and Observations}

Every day people move - they relocate from rental housing to become owners, to be near jobs, to access better schools and to improve their neighbourhoods. Matrices of mobility across communities are useful ways of capturing the amount of movement and of the extent of social fluidity in our communities. We see from this analysis that where you are, is likely to be where you will be. There is long term resilience in the structure of flows within and across communities. Still, the study shows that across these quite different national contexts about a quarter of the moves are significant positive shifts in community status. While we would not expect all the cells to be populated equally, we are able with this analysis to measure just how much movement there is within the system, and whether or not there is overall advantage in the movement, and whether the flows are creating concentrations of disadvantage and advantage.

The matrices also speak to the issues of how to intervene in the urban fabric and whether to address places or people. At this point there are no clear-cut answers to the question, but it is obvious that there is considerable division between the processes which are continuing the concentration of large numbers of the population in both the low and high ends of the distribution across places. In Australia in particular, with the panel data, it is very clear that the likelihood of "falling down" to areas of lower advantage is quite modest which means in the long run that areas which are advantaged will likely stay advantaged, and areas which are less advantaged 
will stay less advantaged. That in turn raises the question (a question posed in the introduction) what is the policy frame work for intervention in the social process. In other words, how to achieve the outcome that the UK government has voiced as an important social project - to increase social fluidity? If low income areas are peopled by low income households what is it that urban intervention can accomplish? Clearly, simply providing exit vouchers as at least one experiment in the US tried will create a situation whereby the most advantaged individuals in the least advantaged areas will exit and will in turn exacerbate poverty concentrations. From a policy perspective, how to intervene in the urban fabric is the difficult if not intractable question which lingers on.

\section{Notes:}

1. I would like to thank Philip Morrison for programming the New Zealand matrices and for observations on how to analyze the probability matrix.

\section{* Acknowledgements}

Access to the New Zealand data used in this study was provided by Statistics New Zealand under conditions designed to give effect to the security and confidentiality provisions of the Statistics Act 1975. The results presented in this study are the work of the author, not Statistics New Zealand. This paper also uses unit record data from the Household, Income and Labour Dynamics in Australia (HILDA) Survey. The HILDA Project was initiated and is funded by the Australian Government Department of Families, Housing, Community Services and Indigenous Affairs (FaHCSIA) and is managed by the Melbourne Institute of Applied Economic and Social Research (Melbourne Institute). The findings and views reported in this paper, however, are those of the author and should not be attributed to either FaHCSIA or the Melbourne Institute.

\section{References}

Andersson, R. and A. Brama (2004). 'Selective migration Swedish distressed neighbourhoods: can area-based urban policies counteract segregation' Housing Studies, Vol. 19, No. 4, 2004

Boheim, R Taylor M. 2002. 'Tied down or room to move? Investigating the relationship between housing tenure, employment status and residential mobility in Britain'. Scottish Journal of Political Economy, 49, 369-392.

Bolt, G. and R. Van Kempen (2003). 'Escaping poverty neighbourhoods in the Netherlands'. Housing Theory and Society, 20: 209-222.
Bolt, G., R. van Kempen, et al. (2008). 'Minority ethnic groups in the Dutch housing market: spatial segregation, relocation dynamics and housing policy’. Urban Studies, 45: 1359-1384.

Cabinet Office (2011). Opening Doors, Breaking Barriers: A Strategy for Social Mobility. London.

Cheshire, P. C., V. Monastiriotis, et al. (2003). 'Income inequality and residential segregation: labour market sorting and the demand for positional goods'. In R. Martin and P. S. Morrison (eds), Geographies of Labour Market Inequality. London, Routledge: 83109.

Cheshire, P. (2012) 'Are mixed community policies evidence based? A review of the research on Neighbourhood Effects'. In Van Ham, M. Manley, D. Bailey,N. Simpson,L. Mclennan, D. (Eds) Neighbourhood Effects Research: New Perspectives. Dordrecht, Springer.

Clark, W.A.V. and Rivers, N. (2012) Clark, William A.V., and Natasha, Rivers. 2012. 'Community Choice in Large Cities: Selectivity and Ethnic Sorting Across Neighbourhoods.' In Maarten Van Ham, David Manley, Nick. Bailey, Ludi. Simpson, and Duncan Maclennan (eds) Understanding Neighbourhood Dynamics: New Insights for Neighbourhood Effects Research, Dordrecht, The Netherlands: Springer: 253-277

Clark, W.A.V. (2012) 'Moving and staying in Los Angeles: Money matters but so does family composition'. Cityscape. Fall

Clark, W.A.V. Van Ham, M. and Coulter, R. (2012) 'Spatial mobility and social outcomes'. Working paper, CCPR, UCLA.

Gramlich, E., D. Laren, et al. (1992). 'Moving into and out of poor urban areas'. Journal of Policy Analysis and Management 11(2): 273-287.

Morrison, P. S. \& Nissen, K. (2010). 'Moving in and out of areas of deprivation: evidence from the New Zealand census'. New Zealand Population Review, 36, 55-80.

Power, A. and J. W. Wilson (2000). 'Social exclusion and the future of cities'. CASE paper 35. London Centre for Analysis of Social Exclusion

Rabe, B. Taylor, M., (2010). 'Residential mobility, quality of neighbourhood and life course events'. Journal of the Royal Statistical Society: Series A 173, 531-555. 
Quillian, L. (2003). 'How long are exposures to poor neighbourhoods? The long-term dynamics of entry and exit from poor neighbourhoods.' Population Research and Policy Review 22(3): 221-249.

Salmond, C. and P. Crampton (2001). 'NZDep96: What does it measure?' Social Policy Journal of New Zealand 17: 82-100.

Schaake, K., Burgers, J. and Mulder, C. (2009) 'Ethnicity at the individual and neighbourhood level as an explanation for moving out of the neighbourhood' Population Research and Policy Review, 29, pp. 593-608.

South, S. J., K. Crowder, and Chavez, E. (2005). 'Exiting and entering high-poverty neighbourhoods: Latinos, Blacks and Anglos compared.' Social Forces 84(2): 873-900.

South, S. J. and K. D. Crowder (1997). 'Escaping distressed neighbourhoods: individual, community, and metropolitan influences'. American Journal of Sociology 102(4): 1040-1084.

South, S.J. Pais, J. and Crowder, K. (2011) 'Metropolitan influences on migration into poor and non- poor neighbourhoods'. Social Science Research 40: 950964

Townsend, P. (1979). Poverty in the United Kingdom. London, Allen Lane and Penquin Books.

Van Ham, M. and P. Feijten (2008). 'Who wants to leave the neighbourhood? The effects of being different from the neighbourhood population on wishes to move.' Environment and Planning A 40(5): 11511170.

White, P., J. Gunston, J., Salmond, C., Atkinson, J. and Crampton, P. (2008). Atlas of socioeconomic deprivation in New Zealand NZDep2006. Wellington Ministry of Health. 